\title{
molecules
}

ISSN 1420-3049

Communication

http://www.mdpi.org

\section{A New Poly-substituted Benzaldehyde from the Leaves of Lysimachia fordiana Oliv.}

\author{
Xin-an Huang ${ }^{1,2, *}$, Ren-zhou Yang ${ }^{2}$ and Wen-di Deng ${ }^{1}$ \\ ${ }^{1}$ Tropical Medicine Institute, Guangzhou University of Traditional Chinese Medicine, Guangzhou \\ 510405, P. R. China; Tel: (+86)-20-36585143; Fax: (+86)-20-86373516; E-mail: xahuang@163.net \\ (Huang), wendy.jang@gmail.com (Deng) \\ 2 South China Botanical Garden of Chinese Academy of Sciences, Guangzhou 510650, P. R. China; \\ Tel: (+86)-20-37252635; E-mail: yangrenzhou@163.com (Yang)
}

* Author to whom correspondence should be addressed; E-mail: xahuang@163.net

Received: 30 November 2006 / Accepted: 17 January 2007 / Published: 22 January 2007

\begin{abstract}
A new poly-substituted benzaldehyde, 1, and a known compound quercetin (2) were isolated from the leaves of Lysimachia fordiana Oliv. The structure of compound $\mathbf{1}$, named fordianol, was determined as 2-heptyl-3,6-dihydroxy-4- methoxybenzaldehyde on the basis of spectroscopic methods. Fordianol did not inhibit the growth of SWO-38 (human brain neuroglioma), MCF-7 (human breast cancer) or HeLa (human cervical carcinoma) cell lines.
\end{abstract}

Keywords: Lysimachia fordiana, 2-heptyl-3,6-dihydroxy-4-methoxybenzaldehyde, cytotoxicity

\section{Introduction}

Having previously reported the isolation of 2-heptyl-6-methoxy-1,4-hydroquinone-1,4-di-O- $\beta$ - $D$ glucopyranoside (fordianoside) and 2-heptyl-6-methoxy-1,4-benzoquinone from the plant Lysimachia fordiana Oliv. (Primulaceae) [1], and in order to further study analogous compounds possessing the 2-heptyl-6- methoxy-1,4-hydroquinone skeleton, we have continued studying this class of compounds. This paper reports the isolation and characterization of two additional compounds from L. fordiana. 


\section{Results and Discussion}

Compound 1 was obtained as yellow needles (from $\mathrm{MeOH}$ ) with a molecular formula of $\mathrm{C}_{15} \mathrm{H}_{22} \mathrm{O}_{4}$ according to the HRESIMS. IR bands at 3073, 1577, $1486 \mathrm{~cm}^{-1}$ and ${ }^{13} \mathrm{C}-\mathrm{NMR}$ data $\delta_{\mathrm{C}} 97.0$ (d), 111.6(s), 129.8 (s), 136.1 (s), 154.1 (s) and 159.9 (s) suggested the presence of a pentasubstituted benzene-ring. A triplet at $\delta 0.85(3 \mathrm{H}, J=6.0 \mathrm{~Hz})$, and several multiplets between $\delta 1.28$ and $2.88 \mathrm{ppm}$ in the ${ }^{1} \mathrm{H}$-NMR spectra combined with an aliphatic methyl and six aliphatic methylene resonances in the ${ }^{13} \mathrm{C}$-NMR spectra revealed the presence of the $n$-heptyl group. The ${ }^{1} \mathrm{H}$ and ${ }^{13} \mathrm{C}$-NMR spectra showed that the molecule contained an aldehyde and a methoxy group. Protons at $\delta_{\mathrm{H}} 12.28$ (exchangeable) and 5.28 (exchangeable) were assigned to two hydroxyl groups, respectively. The connections of the five substituents with the aromatic ring were obtained from the HMBC spectra (Figure 1).

Figure 1. The HMBC spectra of (1).

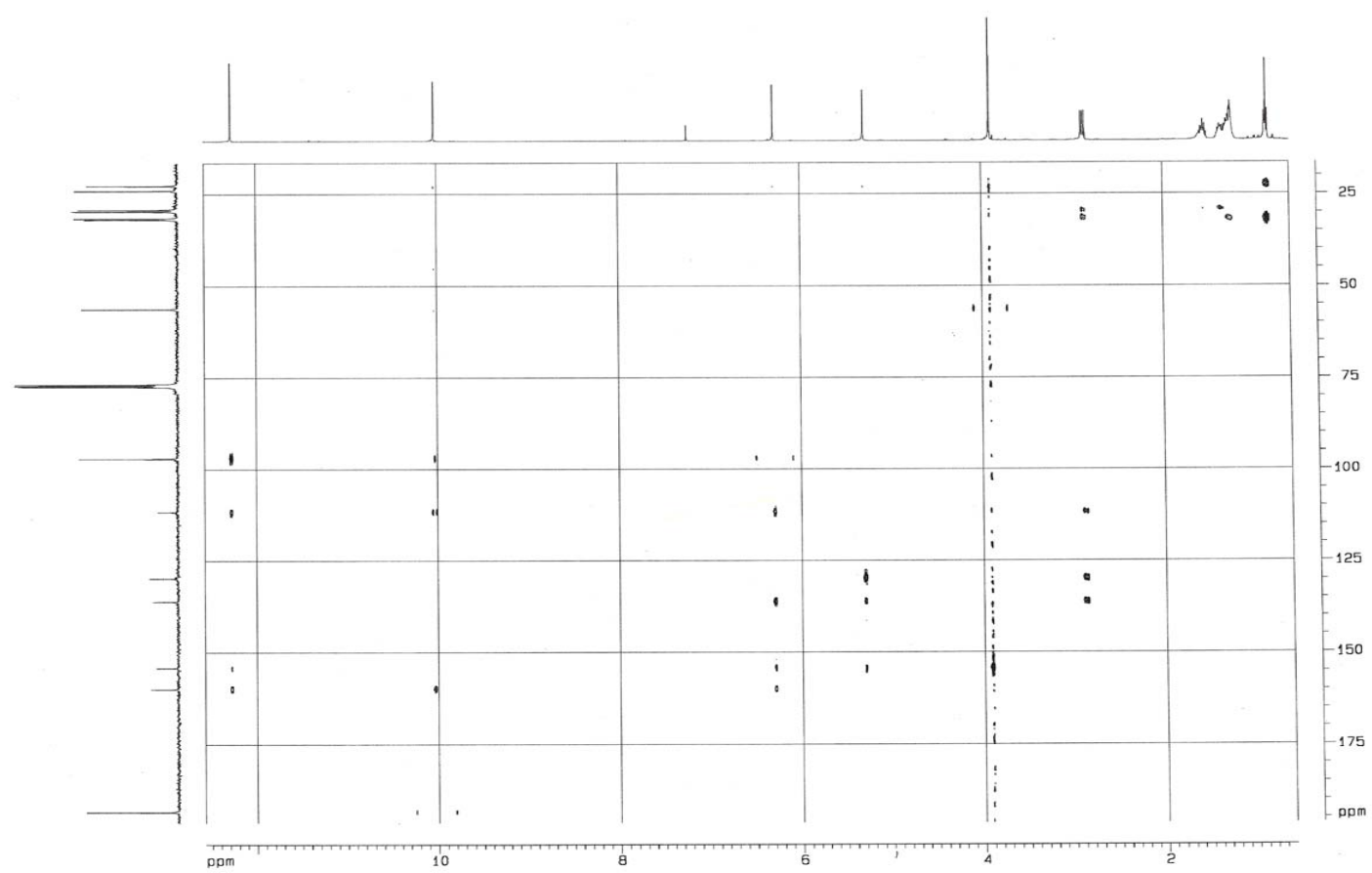

The HMBC correlations from the protons at $\delta 2.88 \mathrm{ppm}$ of the $n$-heptyl group to carbons at $\delta 136.1$, 129.8 and $111.6 \mathrm{ppm}$, the hydroxyl proton at $\delta 5.28 \mathrm{ppm}$ to carbons at $\delta 129.8,136.1$ and $154.1 \mathrm{ppm}$, the methoxy protons to carbon at $\delta 154.1 \mathrm{ppm}$, and the aromatic proton at $\delta 6.30 \mathrm{ppm}$ to carbons at $\delta$ 136.1, 154.1, 159.9, $111.6 \mathrm{ppm}$ indicated the $n$-heptyl group, the hydroxyl moiety at $\delta 5.28 \mathrm{ppm}$ and the methoxy moiety were connected to the carbons at $\delta 129.8,136.1$ and $154.1 \mathrm{ppm}$, respectively, while the formaldehyde group and the hydroxyl moiety at $\delta 12.28 \mathrm{ppm}$ were connected to carbons at $\delta$ 111.6 and $159.9 \mathrm{ppm}$, respectively, as the aromatic carbon at $\delta 159.9 \mathrm{ppm}$ was an oxygenated-carbon (Figure 2). 
Figure 2. Important HMBC correlations of (1).

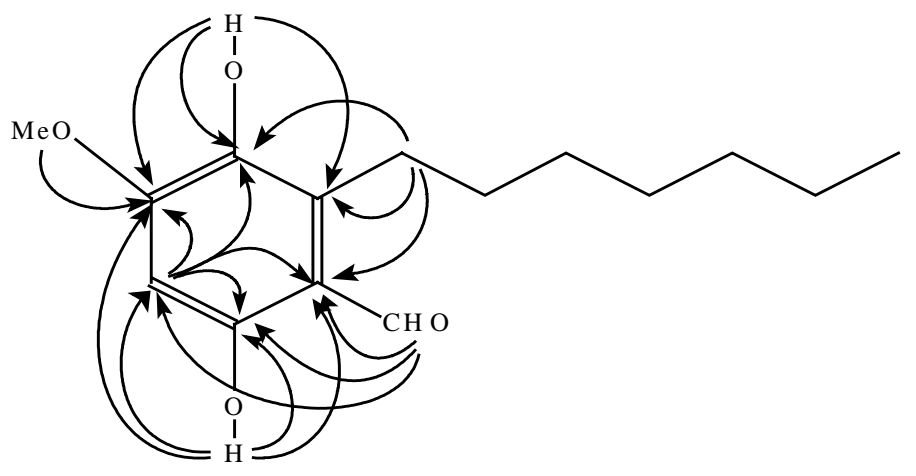

Further confirmation was provided via a selective NOE experiment (Figure 3), in which the aliphatic proton didn't show any correlation to the methoxyl protons. The aldehyde proton at $\delta 10.03$ ppm showed NOE correlations to the hydroxyl proton at $\delta 12.28 \mathrm{ppm}$, and aliphatic protons at $\delta 2.88$ and $1.56 \mathrm{ppm}$, respectively. The NOE correlations from the hydroxyl proton at $\delta 5.28 \mathrm{ppm}$ to the methoxy protons at $\delta 3.90 \mathrm{ppm}$ and the phenethyl protons at $\delta 1.56 \mathrm{ppm}$, the methoxy protons at $\delta 3.90$ ppm to the hydroxyl proton at $\delta 5.28 \mathrm{ppm}$ and the aromatic proton at $\delta 6.30 \mathrm{ppm}$ were observed (Figure 4). Consequently, the structure of compound 1 was elucidated as 2-heptyl-3,6-dihydroxyl-4methoxybenzaldehyde. The biological activity of compound 1 against the SWO-38, MCF-7 and HeLa cell lines was evaluated. The assay results indicated that compound $\mathbf{1}$ did not show any cytotoxicity against these lines, compared with the control.

Compound 2 was identified as quercetin by comparison to literature data [2].

Figure 3. The NOE spectra of (1).

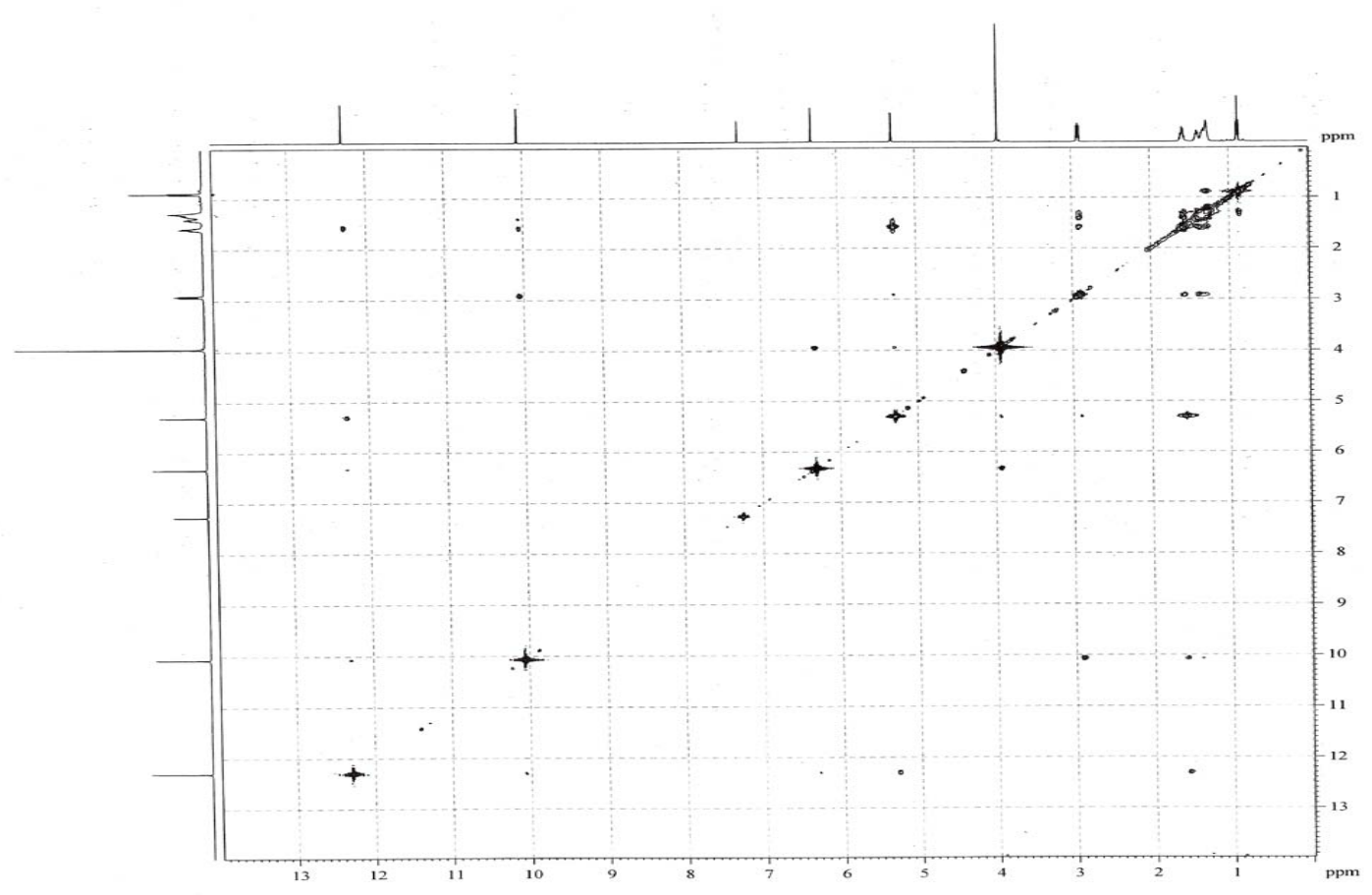


Figure 4. The main NOE correlations of (1).

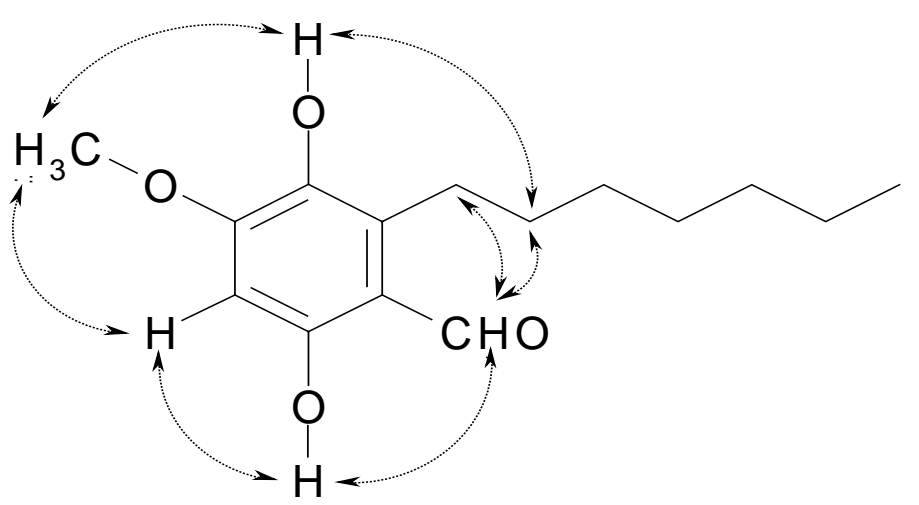

\section{Conclusions}

A new compound named fordianol (1) and a known compound quercetin (2) were isolated from the leaves of L. fordiana. The structure of $\mathbf{1}$ was determined as 2-heptyl-3,6-dihydroxy-4methoxybenzaldehyde mainly by spectroscopic analysis. Three compounds possessing the 2-heptyl-6-methoxy-1,4-hydroquinone skeleton have been isolated from the plant L. fordiana, however, their metabolic relationship is not clear [1].

\section{Experimental}

\section{General}

Melting points were determined using a SGW X-4 micromelting point apparatus and are uncorrected. UV and IR spectra were obtained on a Shimadzu UV-2550 and an Analect RFX-65A spectrometer, respectively. Nuclear magnetic resonance (NMR) spectra were measured on a Bruker DRX-400 spectrometer (400 MHz for ${ }^{1} \mathrm{H}$ and $100 \mathrm{MHz}$ for ${ }^{13} \mathrm{C}$ spectra) using the solvent $\mathrm{CDCl}_{3}$ with TMS as the internal standard. ${ }^{13} \mathrm{C}$ DEPT, HSQC, HMBC and NOESY NMR spectra were obtained using standard Bruker pulse sequences [3]. Chemical shifts are expressed in $\delta$ values with reference to TMS, and coupling constants $(J)$ were given in Hz. HRESIMS and EIMS were recorded on a Bio TOF-Q and a Micromass Platform II spectrometer, respectively.

\section{Plant material}

L. fordiana plants were collected from Wuzhishan Mountains of Guangdong province in July 2003. The voucher specimen (Gang Hao, 387) was authenticated by Prof. Chi-ming Hu, and deposited at the Herbarium of South China Botanical Garden of Chinese Academy of Sciences.

\section{Extraction and isolation}

Dried leaves $(2.3 \mathrm{Kg})$ were extracted with ethanol for three times at room temperature. After defatting with petroleum ether and washing by warm water, the concentrated extract (350 g) was 
subjected to silica gel column chromatography eluting with petroleum ether-acetone gradients. Combination of similar fractions according to TLC analysis afforded two yellow fractions which eluted by 96:4 and 65:35 (v/v), respectively. Fraction 1 was rechromatographed over Sephadex LH-20 eluting with acetone to afford pure 1 (8 mg), Fraction 2 was rechromatographed over silica gel eluting with 65:35 (v/v) pet. ether-acetone to afford pure 2 (14 mg). Compound 1: yellow needles; mp 101-102 ${ }^{\circ} \mathrm{C}$; UV (MeOH) $\lambda_{\max } \mathrm{nm}(\log \varepsilon): 244$ (4.09), 281 (4.05), 292 (4.04), 364 (3.75) nm; IR $v_{\max }^{K B r} \mathrm{~cm}^{-1}$ : $3382(\mathrm{OH}), 1629$ (benzaldehyde C=O), 1577 and $1486(\mathrm{Ph}), 1467,1378,1247(\mathrm{C}-\mathrm{O})$, 1193, 1149, $1056 \mathrm{~cm}^{-1}$; ${ }^{1} \mathrm{H}$ and ${ }^{13} \mathrm{C}-\mathrm{NMR}$ spectral data are listed in Table 1; EIMS m/z (rel. int.): [M] ${ }^{+}$ 266 (100), 248 (12), 233 (5), 219 (15), 205 (95), 195 (52), 181 (63), 177 (77), 153 (52), 125 (23), 69 (58); Negative HRESIMS m/z: 265.1427 [M- H] $]^{+}$calcd for $\mathrm{C}_{15} \mathrm{H}_{21} \mathrm{O}_{4}, 265.1437$ ).

Table 1. NMR spectral data of compound $1\left(\mathrm{CDCl}_{3}\right)$.

\begin{tabular}{llll}
\hline Position & ${ }^{13} \mathrm{C}$ & ${ }^{1} \mathrm{H}$ & HMBC \\
\hline 1 & $111 \mathrm{f}$ & & \\
2 & 129.8 & & \\
3 & 136.1 & & \\
4 & 154.1 & & $111.6,136.1,154.1,159.9$ \\
5 & 97.0 & $6.30(\mathrm{~s}, 1 \mathrm{H})$ & \\
6 & 159.9 & & $29.5,31.5,111.6,129.8$, \\
$1^{\prime}$ & 24.0 & $2.88(\mathrm{t}, 2 \mathrm{H}, \mathrm{J}=8.0 \mathrm{~Hz})$ & $24.0,29.1$ \\
$2^{\prime}$ & 31.5 & $1.56(\mathrm{~m}, 2 \mathrm{H})$ & 29.1 \\
$3^{\prime}$ & 29.5 & $1.35(\mathrm{~m}, 2 \mathrm{H})$ & 31.8 \\
$4^{\prime}$ & 29.1 & $1.28(\mathrm{~m}, 2 \mathrm{H})$ & \\
$5^{\prime}$ & 31.8 & $1.28(\mathrm{~m}, 2 \mathrm{H})$ & 31.8 \\
$6^{\prime}$ & 22.6 & $1.28(\mathrm{~m}, 2 \mathrm{H})$ & $22.6,31.8$ \\
$7^{\prime}$ & 14.1 & $0.85(\mathrm{t}, 3 \mathrm{H}, \mathrm{J}=6 \mathrm{~Hz})$ & $97.0,111.6,159.9$ \\
$1^{\prime}-\mathrm{CHO}$ & 193.4 & $10.03(\mathrm{~s}, 1 \mathrm{H})$ & $129.8,136.1,154.1$ \\
$3-\mathrm{OH}$ & & $5.28(\mathrm{~s}, 1 \mathrm{H}$, exchangeable) & 154.1 \\
$4-\mathrm{OCH}$ & & \\
6-OH & 56.2 & $3.90(\mathrm{~s}, 3 \mathrm{H})$ & $97.0,111.6,154.1,159.9$ \\
\hline
\end{tabular}

\section{Cytotoxicity Assays}

The SWO-38 (human brain neuroglioma), MCF-7 (human breast cancer) and HeLa (human cervical carcinoma) cell lines were cultured at $37{ }^{\circ} \mathrm{C}$ in RPMI 1640 medium supplemented with $10 \%$ (v/v) fetal bovine serum (FBS) in a humidified atmosphere of $95 \%$ air and $5 \% \mathrm{CO}_{2}$. The cells $(1.5 \mathrm{x}$ $10^{4}$ cells/well) were cultured in 96-microwell plates for $24 \mathrm{~h}$, and then solution (100 $\left.\mu \mathrm{L}\right)$ containing the test compounds at various concentrations $(100,25,6.25,1.25,0.39 \mu \mathrm{g} / \mathrm{mL})$ was added to each well. The plates were kept in an incubator for another $24 \mathrm{~h}$. After staining by addition of CCK-8 (10 $\mu \mathrm{L})$ to each well, the plates were further incubated for $2 \mathrm{~h}$. The absorbance was read out on a microplate reader using a test wavelength of $450 \mathrm{~nm}$. The dose response curve was plotted for each tested sample, 
and the concentration giving the average toxic concentration $\left(\mathrm{TC}_{50}\right)$ was calculated.

\section{Acknowledgements}

We thank Prof. Chi-ming Hu for identifying the plant material, and we would also like to acknowledge funding support from the National Natural Science Foundation of China (30500052).

\section{References}

1. Huang, X. A.; Yang, R. Z. A new hydroquinone diglucoside from Lysimachia fordiana. Chem. Nat. Compd. 2004, 40, 457-459.

2. Markham, K. R.; Ternal, B.; Stanley, R.; Geiger, H.; Mabry, T. J. Carbon-13 NMR studies of flavonoids-III. Tetrahedron 1978, 34, 1389-1397.

3. Braun, S.; Kalinowski, H.-O.; Berger, S. 150 and More Basic NMR Experiments: A Practical Course, 2nd expanded ed.; VCH: Weinheim, 1998; pp 460-463.

Sample Availability: Available from the authors.

(C) 2007 by MDPI (http://www.mdpi.org). Reproduction is permitted for noncommercial purposes. 